NASA/TM-2004-212888

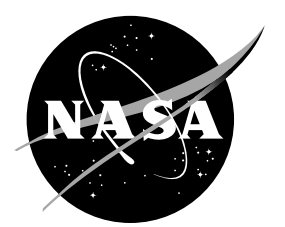

\title{
Performance Evaluation of Fiber Bragg Gratings at Elevated Temperatures
}

Jeffrey Juergens and Grigory Adamovsky Glenn Research Center, Cleveland, Ohio

Bertram Floyd

Akima Corporation, Fairview Park, Ohio 
Since its founding, NASA has been dedicated to the advancement of aeronautics and space science. The NASA Scientific and Technical Information (STI) Program Office plays a key part in helping NASA maintain this important role.

The NASA STI Program Office is operated by Langley Research Center, the Lead Center for NASA's scientific and technical information. The NASA STI Program Office provides access to the NASA STI Database, the largest collection of aeronautical and space science STI in the world. The Program Office is also NASA's institutional mechanism for disseminating the results of its research and development activities. These results are published by NASA in the NASA STI Report Series, which includes the following report types:

- TECHNICAL PUBLICATION. Reports of completed research or a major significant phase of research that present the results of NASA programs and include extensive data or theoretical analysis. Includes compilations of significant scientific and technical data and information deemed to be of continuing reference value. NASA's counterpart of peerreviewed formal professional papers but has less stringent limitations on manuscript length and extent of graphic presentations.

- TECHNICAL MEMORANDUM. Scientific and technical findings that are preliminary or of specialized interest, e.g., quick release reports, working papers, and bibliographies that contain minimal annotation. Does not contain extensive analysis.

- CONTRACTOR REPORT. Scientific and technical findings by NASA-sponsored contractors and grantees.
- CONFERENCE PUBLICATION. Collected papers from scientific and technical conferences, symposia, seminars, or other meetings sponsored or cosponsored by NASA.

- SPECIAL PUBLICATION. Scientific, technical, or historical information from NASA programs, projects, and missions, often concerned with subjects having substantial public interest.

- TECHNICAL TRANSLATION. Englishlanguage translations of foreign scientific and technical material pertinent to NASA's mission.

Specialized services that complement the STI Program Office's diverse offerings include creating custom thesauri, building customized databases, organizing and publishing research results ... even providing videos.

For more information about the NASA STI Program Office, see the following:

- Access the NASA STI Program Home Page at http://www.sti.nasa.gov

- E-mail your question via the Internet to help@sti.nasa.gov

- Fax your question to the NASA Access Help Desk at 301-621-0134

- Telephone the NASA Access Help Desk at 301-621-0390

- Write to:

NASA Access Help Desk

NASA Center for AeroSpace Information 7121 Standard Drive

Hanover, MD 21076 
NASA/TM-2004-212888

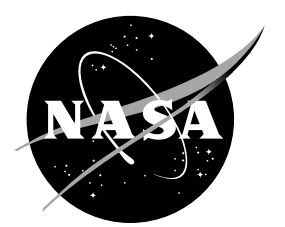

\section{Performance Evaluation of Fiber Bragg Gratings at Elevated Temperatures}

Jeffrey Juergens and Grigory Adamovsky

Glenn Research Center, Cleveland, Ohio

Bertram Floyd

Akima Corporation, Fairview Park, Ohio

Prepared for the

Photonics East Symposium

sponsored by the International Society of Optical Engineering

Providence, Rhode Island, October 27-30, 2003

National Aeronautics and

Space Administration

Glenn Research Center 
This work was sponsored by the Low Emissions Alternative Power Project of the Vehicle Systems Program at the NASA Glenn Research Center.

Available from

NASA Center for Aerospace Information 7121 Standard Drive

Hanover, MD 21076
National Technical Information Service 5285 Port Royal Road Springfield, VA 22100

Available electronically at http:/ /gltrs.grc.nasa.gov 


\title{
Performance Evaluation of Fiber Bragg Gratings at Elevated Temperatures
}

\author{
Jeffrey Juergens and Grigory Adamovsky \\ National Aeronautics and Space Administration \\ Glenn Research Center \\ Cleveland, Ohio 44135 \\ Bertram Floyd \\ Akima Corporation \\ Fairview Park, Ohio 44126
}

\begin{abstract}
The development of integrated fiber optic sensors for smart propulsion systems demands that the sensors be able to perform in extreme environments. In order to use fiber optic sensors effectively in an extreme environment one must have a thorough understanding of the sensor's limits and how it responds under various environmental conditions. The sensor evaluation currently involves examining the performance of fiber Bragg gratings at elevated temperatures.

Fiber Bragg gratings (FBG) are periodic variations of the refractive index of an optical fiber. These periodic variations allow the FBG to act as an embedded optical filter passing the majority of light propagating through a fiber while reflecting back a narrow band of the incident light. The peak reflected wavelength of the FBG is known as the Bragg wavelength. Since the period and width of the refractive index variation in the fiber determines the wavelengths that are transmitted and reflected by the grating, any force acting on the fiber that alters the physical structure of the grating will change what wavelengths are transmitted and what wavelengths are reflected by the grating. Both thermal and mechanical forces acting on the grating will alter its physical characteristics allowing the FBG sensor to detect both temperature variations and physical stresses, strain, placed upon it. This ability to sense multiple physical forces makes the FBG a versatile sensor.
\end{abstract}

This paper reports on test results of the performance of FBGs at elevated temperatures. The gratings looked at thus far have been either embedded in polymer matrix materials or freestanding with the primary focus of this paper being on the freestanding FBGs. Throughout the evaluation process, various parameters of the FBGs performance were monitored and recorded. These parameters include the peak Bragg wavelength, the power of the Bragg wavelength, and total power returned by the FBG. Several test samples were subjected to identical test conditions to allow for statistical analysis of the data. Test procedures, calibrations, and referencing techniques are presented in the paper along with directions for future research.

\section{INTRODUCTION}

With the work of Hill et al. on the photosensitivity of optical waveguides in 1978 allowing the creations of filters in optical waveguides, a whole new world of fiber optic devices has been opened up. ${ }^{1}{ }^{1}$ From high density optical data transmission to optical fibers themselves acting as sensors, the possibilities are far-reaching. With the ability of the optical fiber to act as a sensor, a whole new range of remote sensing possibilities was created. With these new possibilities comes the need to thoroughly understand the devices themselves. In the case of the FBG one must have a full understanding of the reaction of the sensor to different physical forces and the effects they will have on the sensors output. Without a thorough understanding of the how the sensor reacts under a range of conditions one cannot use the full capabilities of the sensor. We are currently working to more thoroughly understand the response of FBGs subjected to thermal forces. We are working on not only understanding the wavelength response of the FBG but also the optical power and spectral change of the sensor. 
The basic principle behind the operation of a FBG is relatively simple. A periodic modulation in the index of refraction, $n$, of an optical fiber's core along the length of the fiber acts as a filter reflecting a specific wavelength while passing others. By varying the spacing of the index variations, $\Lambda$, one can tune the fiber optic filter to reflect a certain wavelength. The wavelength reflected is called the Bragg wavelength, $\lambda_{B}$, and is given by $\lambda_{B}=2 \Lambda n$. Since the Bragg wavelength of the grating is dependent on the spacing of the index variations, the Bragg wavelength can be altered by physical forces which alter the spacing of the gratings. These forces most often take the form of a strain placed along the axis of the fiber or thermal forces expanding the length of the FBG. The shift in the Bragg wavelength, in terms of both a change in the FBG's length, $\Delta l$, and its temperature, $\Delta T$, can be represented as: ${ }^{2}$

$$
\Delta \lambda_{B}=2\left(\Lambda \frac{\partial n}{\partial l}+n \frac{\partial \Lambda}{\partial l}\right) \Delta l+2\left(\Lambda \frac{\partial n}{\partial T}+n \frac{\partial \Lambda}{\partial T}\right) \Delta T
$$

The temperature and strain induced Bragg wavelength shifts can separated out and be represented individually as:

$$
\begin{gathered}
\text { Strain: } \Delta \lambda_{B}=\lambda_{B}\left(1-p_{e}\right) \varepsilon_{z} \\
\text { Temperature: } \Delta \lambda_{B}=\lambda_{B}(\alpha+\zeta) \Delta T
\end{gathered}
$$

where $p_{e}$ is an effective strain-optic constant, $\varepsilon_{z}$ is the induced strain along the axis of the grating, $\alpha$ is the thermal expansion of the fiber, and $\zeta$ is the thermo-optic coefficient. The temperature dependence for a silica fiber has been found to typically be 1.0 to $1.19 \mathrm{~nm}$ per $100{ }^{\circ} \mathrm{C}$ at $1300 \mathrm{~nm}^{2-4}$

Preliminary evaluation of FBGs consisted of evaluation of gratings embedded in polymer matrix composite panels. ${ }^{5,65}$ This work looked at the feasibility of using embedded FBGs as strain sensors for aerospace integrated vehicle health management. The study was particularly interested in the use of FBGs at elevated temperature up to $300{ }^{\circ} \mathrm{C}$. In the preliminary evaluation of the FBG sensors, the temperature dependence of the Bragg wavelength shift proved to be very repeatable. The reflected power level from the grating did show the same consistency. The reflected power levels in these preliminary evaluations seemed to indicate a degradation of the reflectivity of the grating on each successive thermal cycle. The reflected power levels also seemed to be somewhat erratic within each thermal cycle. This loss of signal from cycle to cycle seemed to indicate a permanent degradation of the grating structure. Some of the variations seen in the FBGs in this preliminary work could have been due to the FBGs in the PMC panels only being annealed to $300{ }^{\circ} \mathrm{C}$. Since this initial work proved promising this led to this follow-on work with specific emphasis placed on the accuracy of the data being taken along with looking more closely at the degradation and thermal stability of FBGs.

\section{TEST SETUP AND PROCEDURE}

Figure 1 shows the test setup used in the re-annealing and thermal cycling of the FBG sensors. The test setup consists of a fiber coupled $1300 \mathrm{~nm}$ light emitting diode light source, SLED, connected to a $2 \times 2$ coupler, coupler 1 . One output of coupler 1 is connected to a photodetector PD1 to monitor the SLED output power. The other branch of the coupler is connected to the FBG under evaluation. For thermal cycling the FBG is placed in an oven capable of reaching $300{ }^{\circ} \mathrm{C}$ while for re-annealing the FBG is placed in a furnace capable of reaching over $400{ }^{\circ} \mathrm{C}$. The reflected light from the Bragg grating goes back through coupler 1 to coupler 2 , another $2 \times 2$ coupler. The outputs of coupler 2 are connected to another photodetector, PD2, and an optical spectrum analyzer, OSA. The optical spectrum analyzer is used to measure the Bragg wavelength of the grating along with its reflected power. Photodetector PD2 is also used to measure the reflected power from the FBG. The output signals from both PD1 and PD2 are monitored using bench-top DMMs. The oven temperature is monitored with a k-type thermocouple positioned adjacent to the FBG. All test equipment being used is outfitted with computer interfaces allowing LabVIEW to be used to control equipment and record data. With LabVIEW data can be recorded consistently and accurately for extended periods of time. 
Special attention was paid to calibration and characterization of equipment being used throughout the evaluation of the FBG sensors. All associated equipment used in the evaluation of the FBGs was carefully tested to verify that the data being recorded were phenomena of the gratings themselves and not the equipment being used. The SLED used was tested for long and short term stability. The stability of the photodetectors was also verified. All other associated test equipment being used was calibrated to NIST traceable standards. In addition, all equipment was allowed to warm up at least 90 min before all testing to minimize the drift of the equipment. All data recording was done using LabVIEW to ensure accurate, consistent data recording. The output of the SLED light source was monitored during all testing to allow for correction of the output of the grating due to variations seen in the light source.

\section{1. $\quad$ Re-Annealing of Fiber Bragg Gratings}

In order to assure the most thermally stable gratings at operating temperatures up to $300{ }^{\circ} \mathrm{C}$, all of the gratings that were evaluated were first re-annealed to $400^{\circ} \mathrm{C}$ before thermal cycling. ${ }^{7-10}{ }^{7}$ Because of the temperature range of the reannealing and thermal cycling evaluation, polyimide coated FBGs were used throughout. All FBGs evaluated were identical models specified as having a $1300 \mathrm{~nm}$ center wavelength with a $0.3 \mathrm{~nm}$ bandwidth. All FBGs were specified as having been annealed to $300{ }^{\circ} \mathrm{C}$ by the manufacturer.

The re-annealing process of the FBGs began by ramping them up to $400{ }^{\circ} \mathrm{C}$ at a rate of $2{ }^{\circ} \mathrm{C} / \mathrm{min}$. The ramp rate was chosen to allow for a relatively short ramp up period while not thermally shocking the FBGs. Once at $400^{\circ} \mathrm{C}$, the FBGs were held there for a period of $12 \mathrm{hr}$. After $12 \mathrm{hr}$ at $400^{\circ} \mathrm{C}$ the FBGs were allowed to cool inside the furnace back to room temperature through convective cooling. The performance of the FBG was monitored throughout the re-annealing process to determine the stability of the grating with data being recorded once a minute. After the first re-annealing cycle, the stability of the gratings reflected output was evaluated. If the output did not stabilize after the first $12 \mathrm{hr}$ of reannealing, the FBG was put through the same re-annealing process again. All FBGs that were re-annealed that did not stabilize in $12 \mathrm{hr}$ appeared to stabilize after a total of $24 \mathrm{hr}$ at $400^{\circ} \mathrm{C}$. Throughout the entire re-annealing process and all other testing performed the Bragg wavelength from all the FBGs was very consistent. The power output of the light source used to monitor the performance of the FBG also remained very stable throughout the re-annealing of the FBGs with variations of less than 0.3 percent. This was after the SLED source was allowed at least 90 min to warm-up. A typical reflected wavelength versus temperature plot from a re-annealing cycle can be seen in Figure 2. This plot clearly shows the thermal hysteresis in the system as the gratings are heated and cooled. The upper line on the plot is the Bragg wavelength of the FBG as the furnace is heated while the lower line is the Bragg wavelength as the furnace cools. The lines do not overlap since the temperature of the FBG lags as the oven heats and cools.

Since the Bragg wavelength of the FBG seemed to behave consistently through the temperature range of interest, the main criteria used to determine if the FBG's output had stabilized was its total reflected power. The total power reflected from each FBG varied greatly during the re-annealing process. In some FBGs the power dropped quickly at the beginning then slowly rose to a point where it stabilized while other FBG did the exact opposite. Others simply dropped or rose to a point where they appeared to stabilize. The only commonality between the FBGs was that the reflected power reached a point where it appeared to stabilize. Two different behaviors of FBGs can be seen in Figure 3 and Figure 4. The data shown in these plots is the average over a 5 min time span. While the gratings in Figure 3 took two 12 hr cycles for its reflected power to stabilize, the grating shown in Figure 4 took only one $12 \mathrm{hr}$ re-annealing cycle to stabilize. Of the 8 FBGs studied during the course of this work, five required two $12 \mathrm{hr}$ re-annealing cycles while three only required one re-annealing cycle. The two other parameters of the FBGs performance that were monitored during the re-annealing process were the peak power level of the Bragg wavelength and the $3 \mathrm{~dB}$ spectral width of the reflected light. While both of these parameters showed some cyclic variation with temperature, neither appeared to be a good indicator of the overall thermal stability of the FBG.

\subsection{Thermal Cycling}

After the re-annealing of the FBGs to $400^{\circ} \mathrm{C}$, they were then cycled between $300{ }^{\circ} \mathrm{C}$ and ambient six times. The FBG was heated from room temperature to $300^{\circ} \mathrm{C}$ at a rate of $1^{\circ} \mathrm{C} / \mathrm{min}$. The slow ramp rate allowed the gratings to heat up evenly and avoid any thermal shock. The slow ramp rate also allowed the FBG and the thermocouple to be at the same temperature. The FBG was then held at $300^{\circ} \mathrm{C}$ for $3 \mathrm{hr}$. After $3 \mathrm{hr}$ at $300^{\circ} \mathrm{C}$ the $\mathrm{FBG}$ was allowed to cool at $1{ }^{\circ} \mathrm{C} / \mathrm{min}$ back to $35^{\circ} \mathrm{C}$. Due to limitations of the oven used for the thermal cycling, a cooling rate of $1{ }^{\circ} \mathrm{C} / \mathrm{min}$ could not be maintained for the entire cooling process. From about 78 to $35^{\circ} \mathrm{C}$ the gratings cooled somewhat slower by means of convection only. Once the grating cooled to $35^{\circ} \mathrm{C}$ the process was immediately repeated five more times for a total of 
six cycles at $300^{\circ} \mathrm{C}$ for a total of $18 \mathrm{hr}$ at $300^{\circ} \mathrm{C}$. Throughout the entire evaluation process, data was recorded on the performance of each FBG once a minute. The peak Bragg wavelength, along with the total and peak power reflected from the grating was recorded. The SLED source output was also monitored and the data recorded on the output of the FBG was corrected for any fluctuations in the SLED output. Fluctuations of no more than 0.3 percent were seen in the SLED source throughout the evaluation process. This was after a minimum of 90 min of warm-up.

Throughout the thermal cycling of the FBG the Bragg wavelength temperature response was very consistent and repeatable. The average of the standard deviations of the temperature to wavelength relationship ranged from 1.86 to $2.92^{\circ} \mathrm{C}$ over the six thermal cycles each grating was subjected too. This is less than 1.0 percent error of full scale throughout the entire evaluation temperature range of ambient to $300^{\circ} \mathrm{C}$. There was no indication of change in the Bragg wavelength response in any of the gratings that were put through the over $80 \mathrm{hr}$ of thermal cycling. A typical example of the observed Bragg wavelength temperature response is shown in Figure 5. This particular FBG has a Bragg wavelength temperature shift of $1.06 \mathrm{~nm}$ per $100^{\circ} \mathrm{C}$. Throughout our evaluation of FBGs, the Bragg wavelength temperature dependence ranged from 1.06 to $1.11 \mathrm{~nm}$ per $100^{\circ} \mathrm{C}$ for all of the FBGs evaluated. This compares favorably with published values of 1.0 to $1.19 \mathrm{~nm}$ per $100^{\circ} \mathrm{C}$ for FBGs at $1300 \mathrm{~nm} .{ }^{22-4}$ The total power reflected from the FBG did not exhibit the same stability and consistency during thermal cycling as the FBGs Bragg wavelength. The total power varied from FBG to FBG considerably, some varying slightly through the thermal cycles while others remained fairly stable. An example of the total reflected power of two of the FBGs during thermal cycling can be seen in Figure 6 and Figure 7. The data shown in these figures is averaged over a 5 min time span. While the return signal strength from the FBG in Figure 6 varied considerably through the thermal cycling process, the output of the FBG in Figure 7 remained much more stable through the duration of the cycling. The third parameter of interest throughout the thermal cycle process was the power level of the Bragg wavelength. The Bragg wavelength power showed a much more cyclic pattern more similar to the Bragg wavelength temperature dependency than the total reflected power. Figure 8 shows a typical example of the power level at the Bragg wavelength throughout the thermal cycling process. While this figure shows the cyclic nature of the Bragg wavelength power level it also shows a slight drift in the power level through the thermal cycling process.

\section{CONCLUSION}

All of the FBGs evaluated have demonstrated a strong and repeatable dependency of their peak wavelength with temperature. The wavelength temperature dependency appears to be almost linear through many thermal cycles and across numerous samples with no sign of thermal hysteresis. In our opinion, the re-annealing of the FBGs to $400{ }^{\circ} \mathrm{C}$ was significant in this role.

With current analysis techniques using an indirect method to determine the Bragg wavelength of the FBG, one must carefully look at the technique being used and the impact a varying power level might have on the sensor's output. These indirect methods use a wavelength-to-intensity conversion with a photodetector to monitor the intensity change from a shift in the Bragg wavelength. Thus, with an analysis technique dependent on the reflected power's intensity level, the error in the readings one gets may have an unexpected error associated with it. Techniques such as using a matched reference grating or an interferometer to measure the shift in Bragg wavelength would both be very sensitive to variations in a power level shift of the reflected signal.

Effects of the variation in reflected power from the FBG may be minimized by introducing a power referencing scheme. Figure 9 shows an example schematic to compensate for a power level shift of the FBG signal. An additional photodetector PD3 would be used to monitor the power level transmitted through the FBG and would be used to compensate the systems for a change in the reflectivity of the FBG.

In order to more fully evaluate the performance of FBGs at elevated temperatures, the thermal stability of such signal parameters as optical bandwidth and background noise should be looked at. The next step would be to attach an FBG to a surface or to imbed gratings in various materials or structures and perform similar tests. A comparison of the results with analytical predictions would give a more complete picture of the thermal behavior of fiber optic Bragg gratings. 


\section{REFERENCES}

1. Hill, K.O., Fuiji, Y., Johnson, D.C., Kawasaki, B.S., "Photosensitivity in Optical Fiber Waveguides: Applications to Reflection Filter Fabrication,” Appl. Phys. Lett., Vol. 32, pp. 647-649, 1978.

2. Othonos, Andreas, "Fiber Bragg Gratings,” Rev. Sci. Instrum., Vol. 68, No. 12, pp. 4309-4341, 1997.

3. Rao, Yun-Jiang, "In-fibre Bragg grating sensors,” Meas. Sci. Tech., Vol. 8, pp. 355-375, 1997.

4. Kersey, A., Davis, M., Patrick, H., LeBlanc, M., Koo, K., Askins, C., Putnam, M., Friebele, E., "Fiber Grating Sensors,” J. Lightwave Tech., Vol. 15(8), pp. 1441-1463, 1997.

5. Velázquez, M., “Revolutionary Aeropropulsion Concepts Co-Op Final Report,” http://www.ece.uprm.edu/ colom/ejemplo2.pdf

6. Adamovsky, G., Lekki, J., Sutter, J.K., Sarkisov, S.S., Curley, M.J., Martin, C.E., "Smart Microsystems with photonic element and their applications to aerospace platforms,” Proc. SPIE, Vol. 4235, pp. 407-418, 2001.

7. Erdogan, T., Mizrahi, W., Lemaire, P.J., Monroe, D., "Decay of ultraviolet-induced Bragg gratings,” J. Appl. Phys., Vol. 76, pp. 73-80, 1994.

8. Patrick, H., Gilbert, S.L., Lidgard, A., Gallagher, M.D., “Annealing of Bragg gratings in hydrogen-loaded optical fiber,” J. Appl. Phys., Vol. 78, pp. 2940-2945, 1995.

9. Rose, A., “Annealing Optical Fiber: Applications and Properties,” American Ceramics Society Bulletin, Vol. 79(3), pp. 40-43, 2000.

10. Rose, A., "The observation of OH in annealed optical fiber," J. Non-Cryst. Solids, Vol. 231, pp. 280-285, 1998.

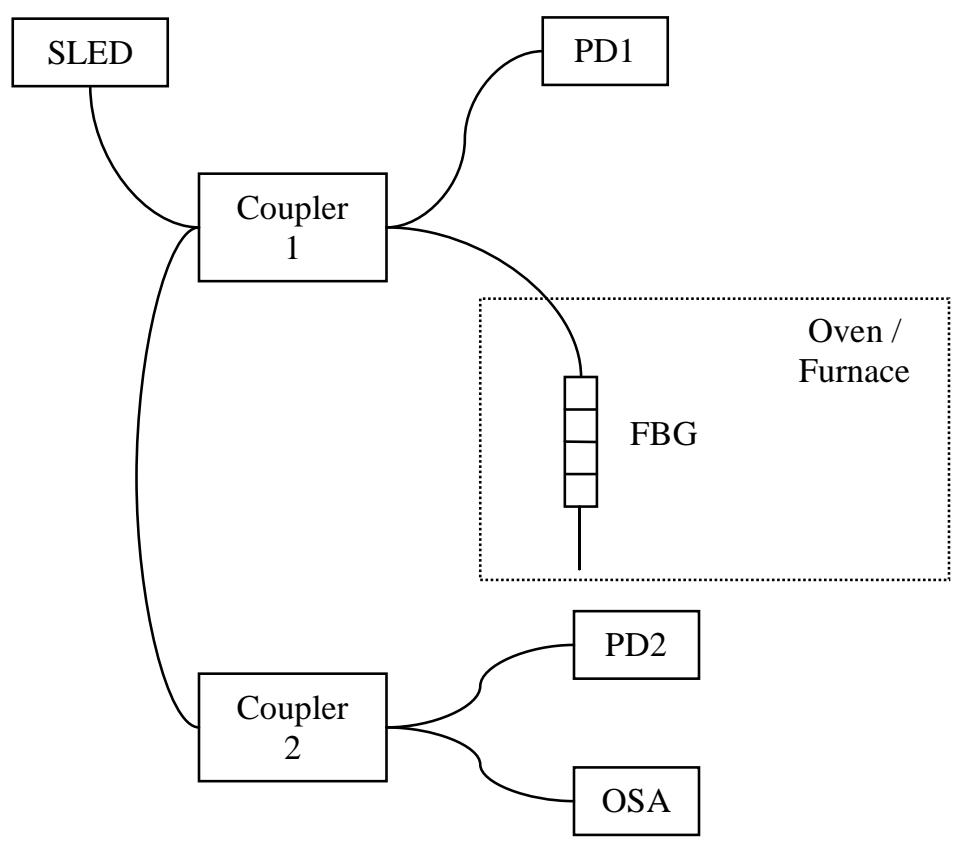

Figure 1.-Fiber Bragg grating re-annealing and thermal cycling test setup. 


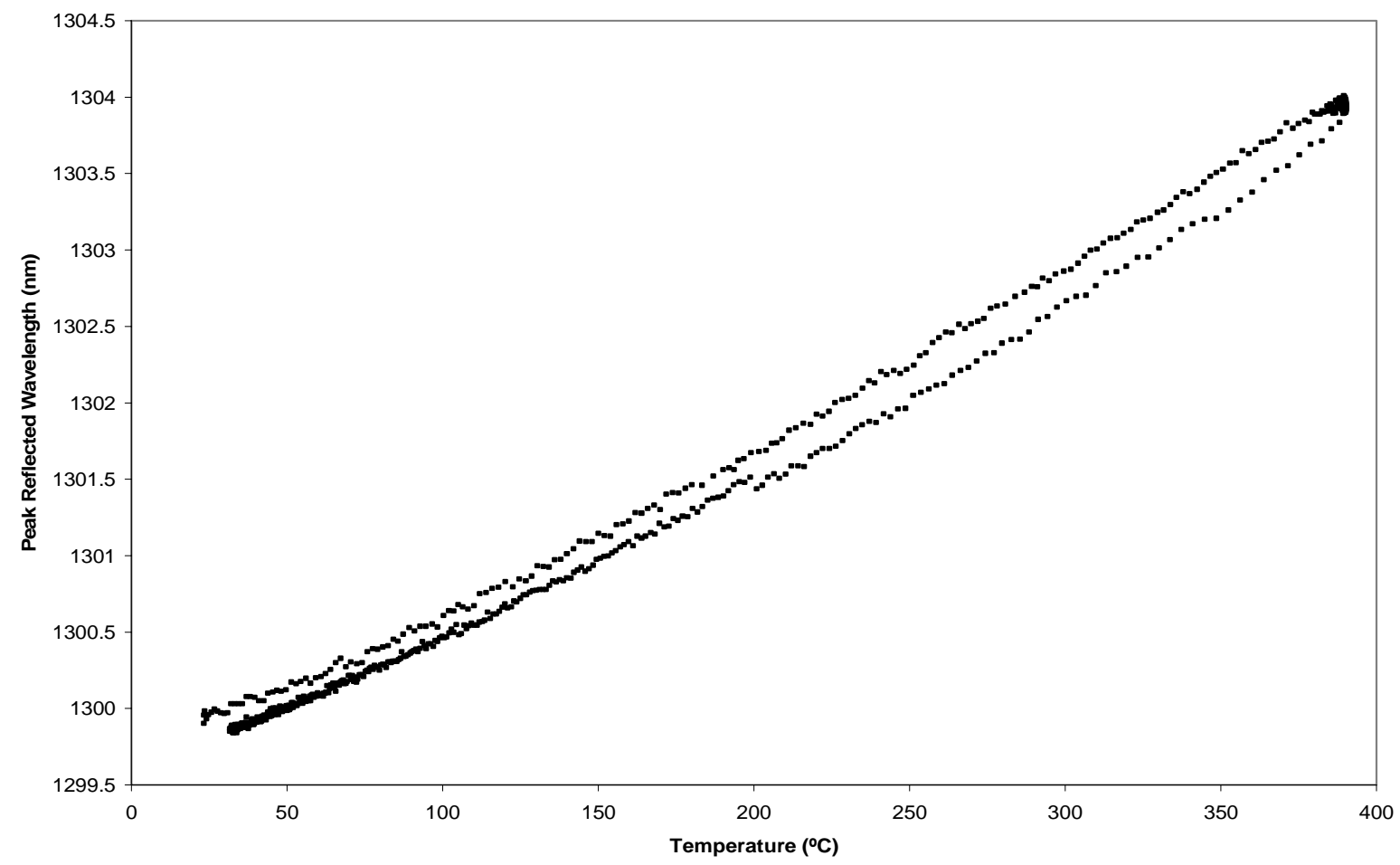

Figure 2.-Peak reflected wavelength temperature dependence during re-annealing process.

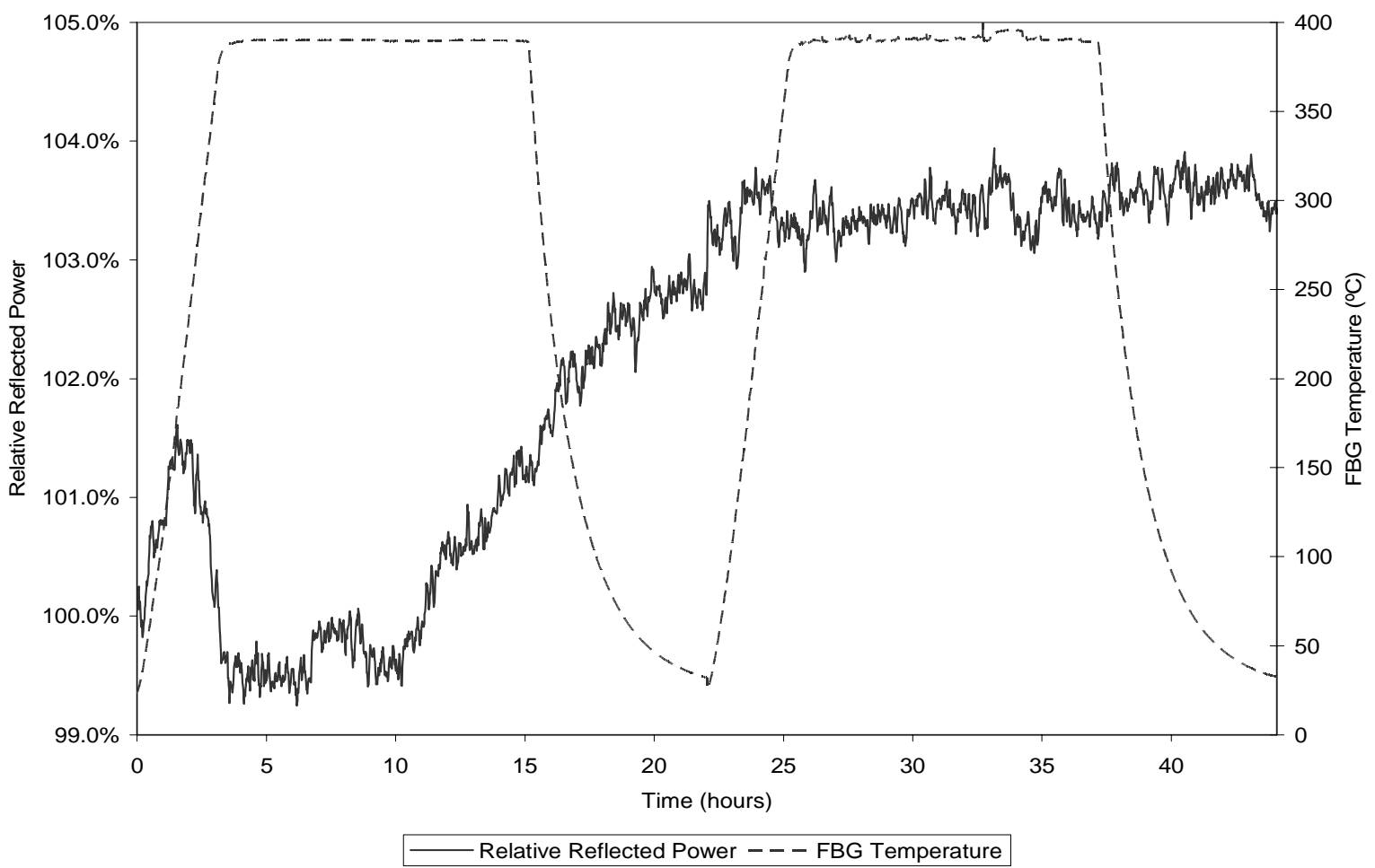

Figure 3._-FBG reflected power during re-annealing process requiring two re-annealing cycles. 


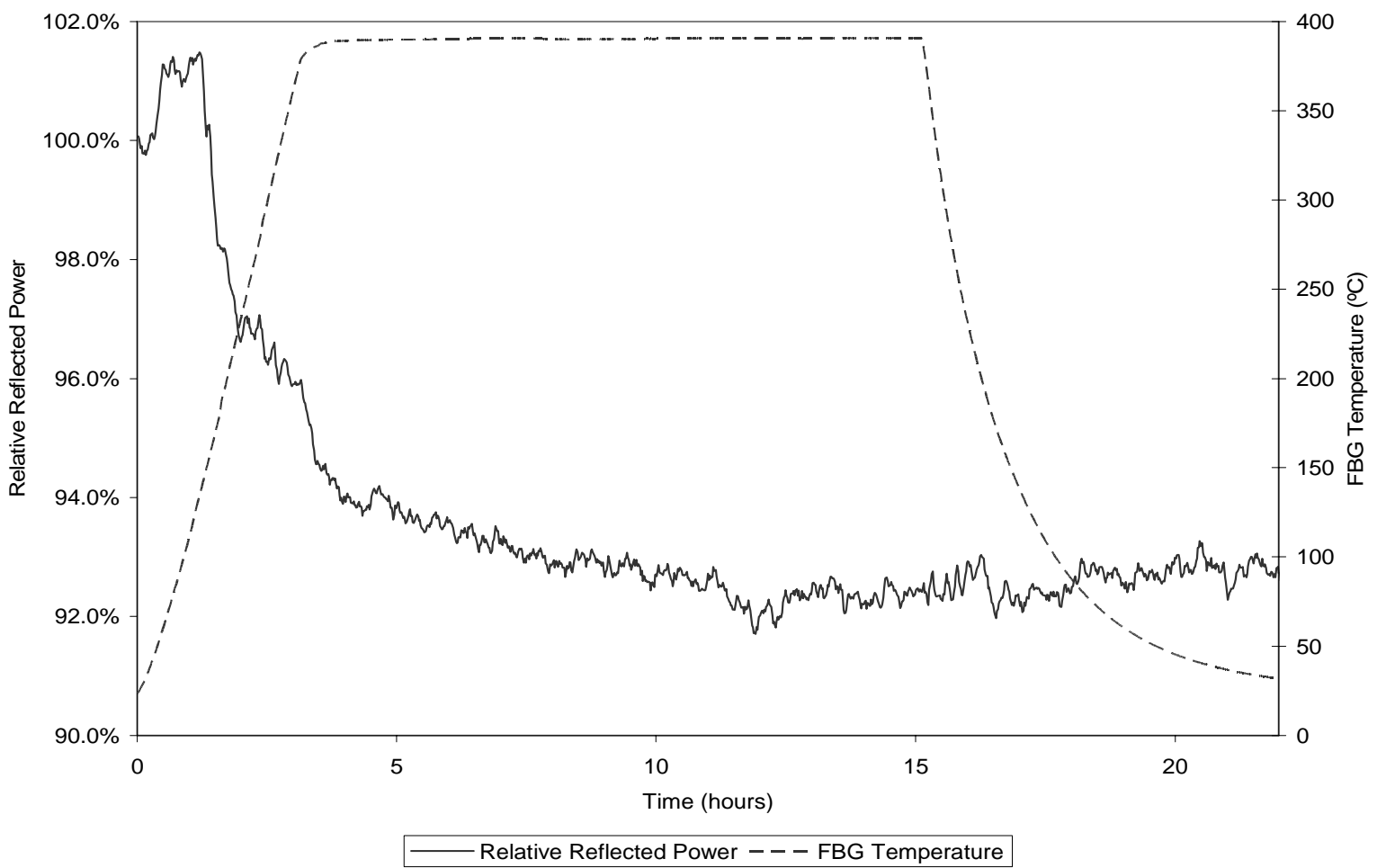

Figure 4.-FBG reflected power during re-annealing process requiring one re-annealing cycle.

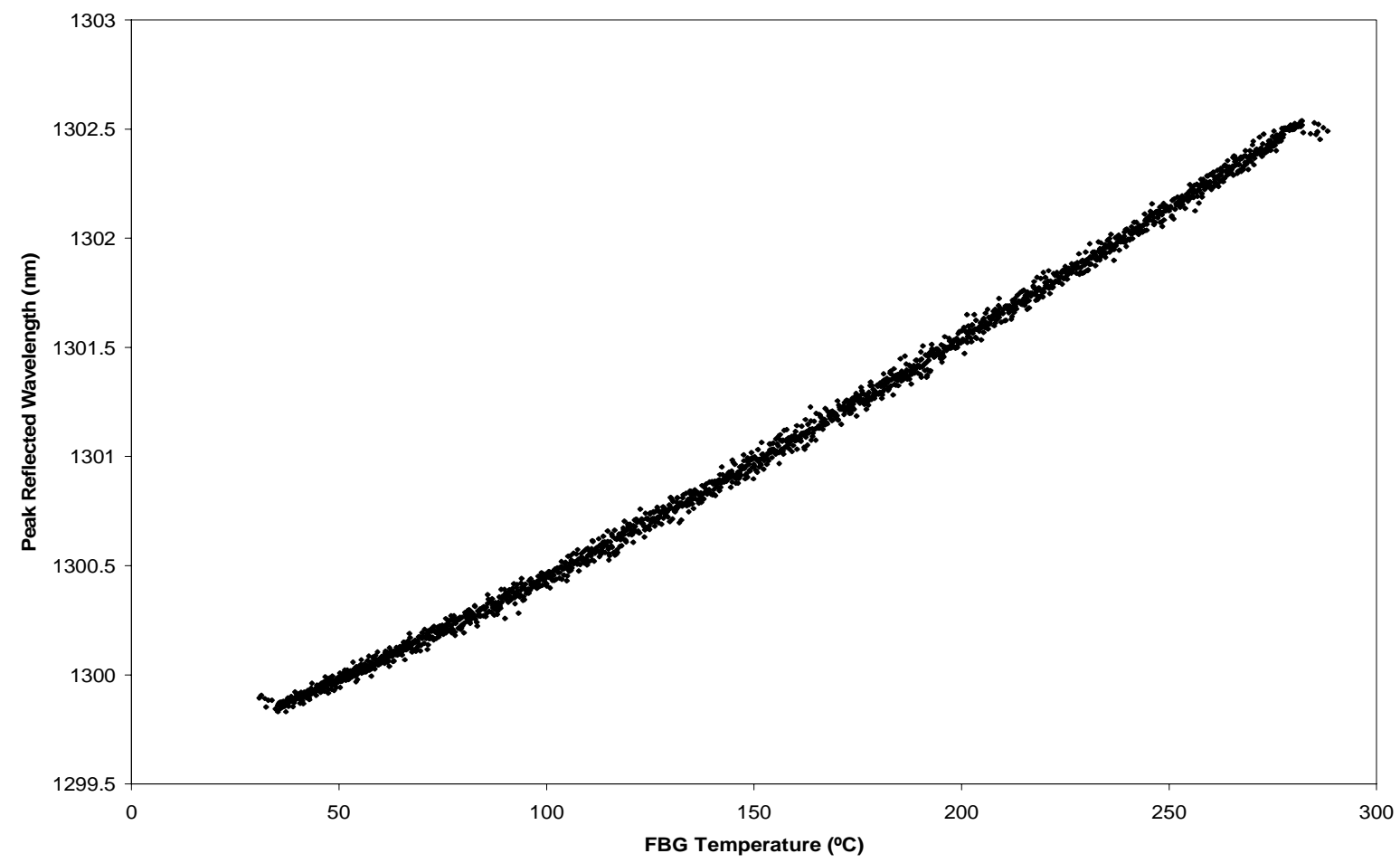

Figure 5.-Bragg wavelength temperature dependence through 6 thermal cycles (80 hr). 


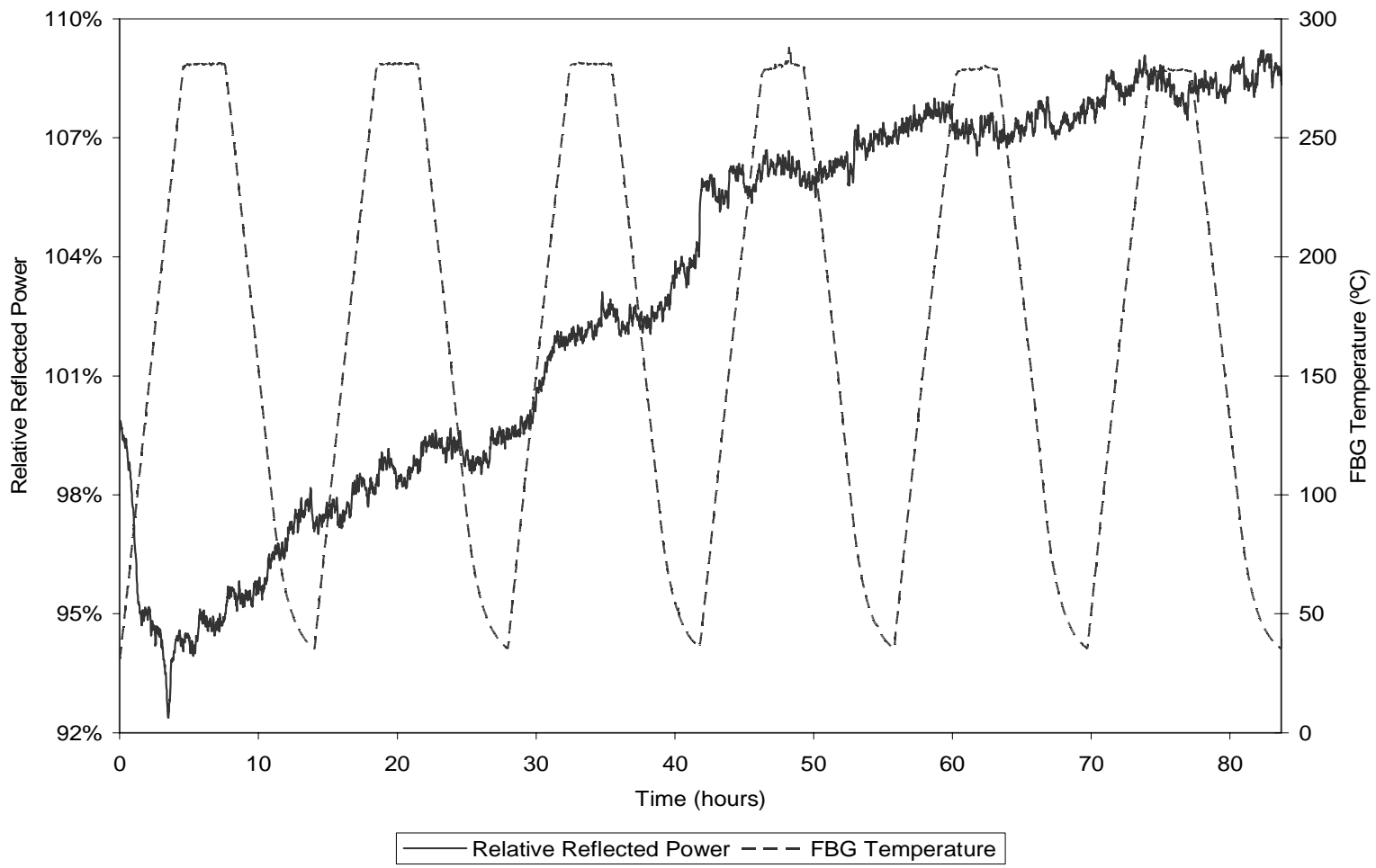

Figure 6.-Re-annealed FBG reflected power during thermal cycling.

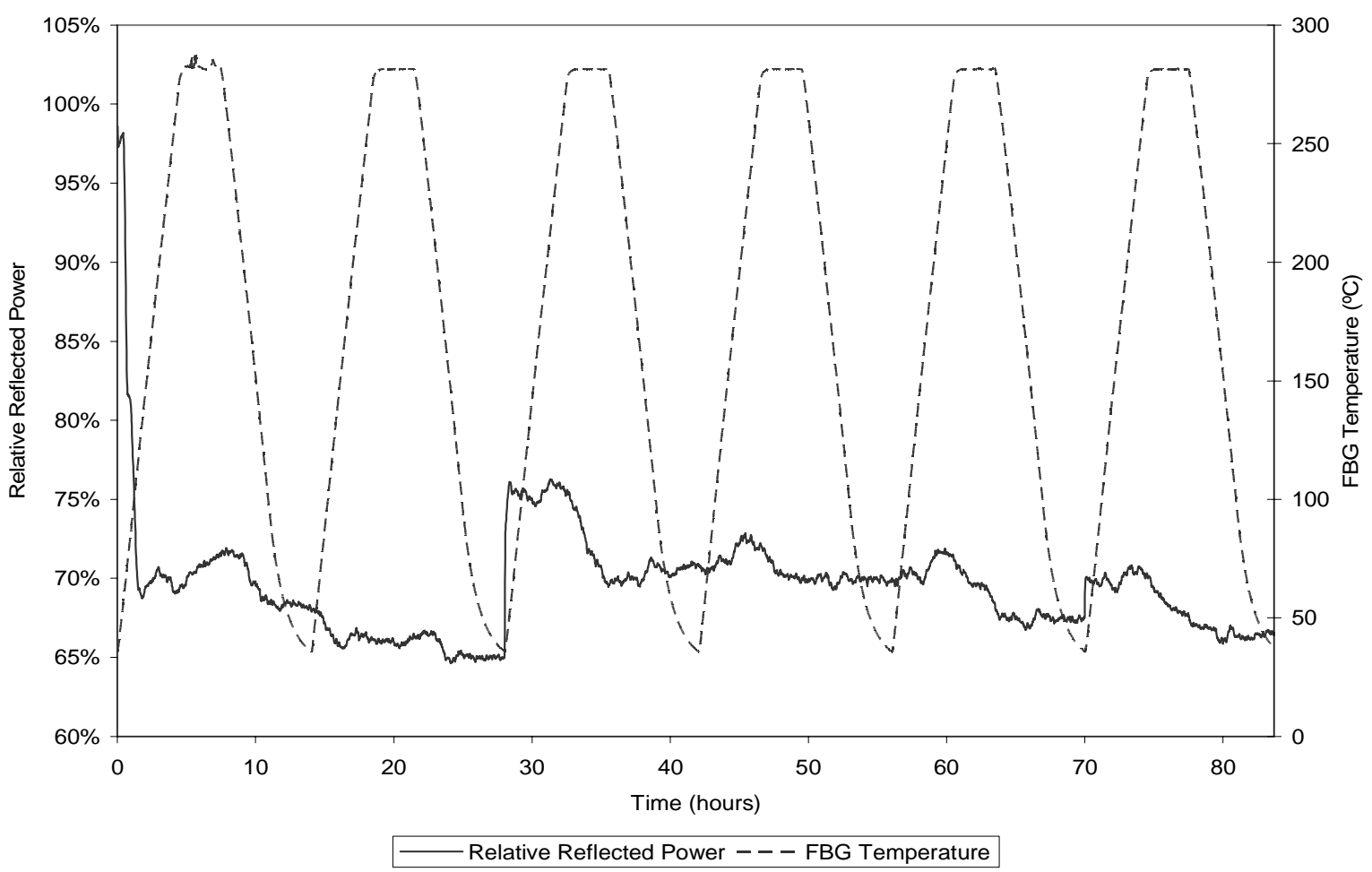

Figure 7.- Re-annealed FBG reflected power during thermal cycling. 


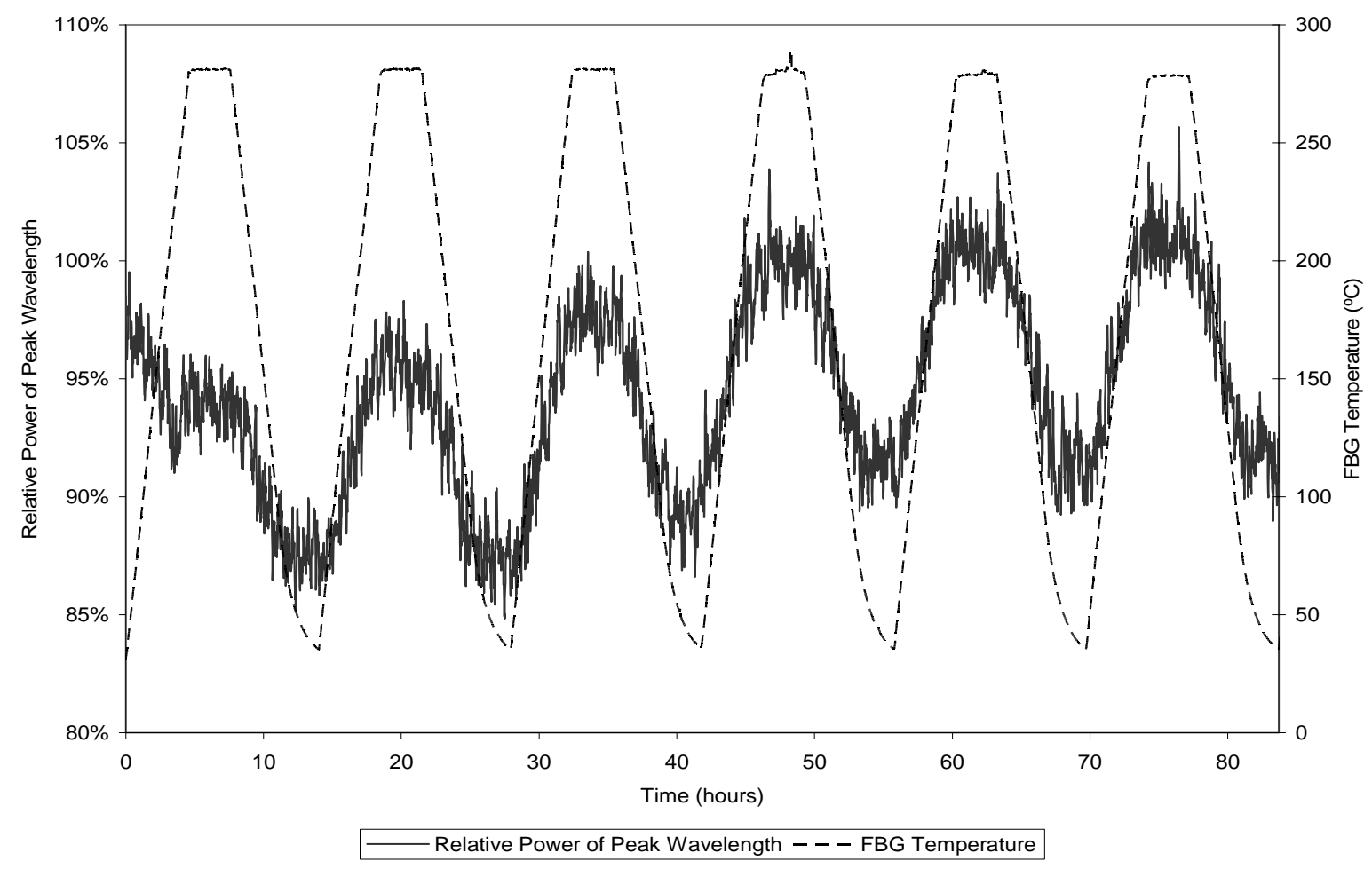

Figure 8.- Relative power of peak wavelength.

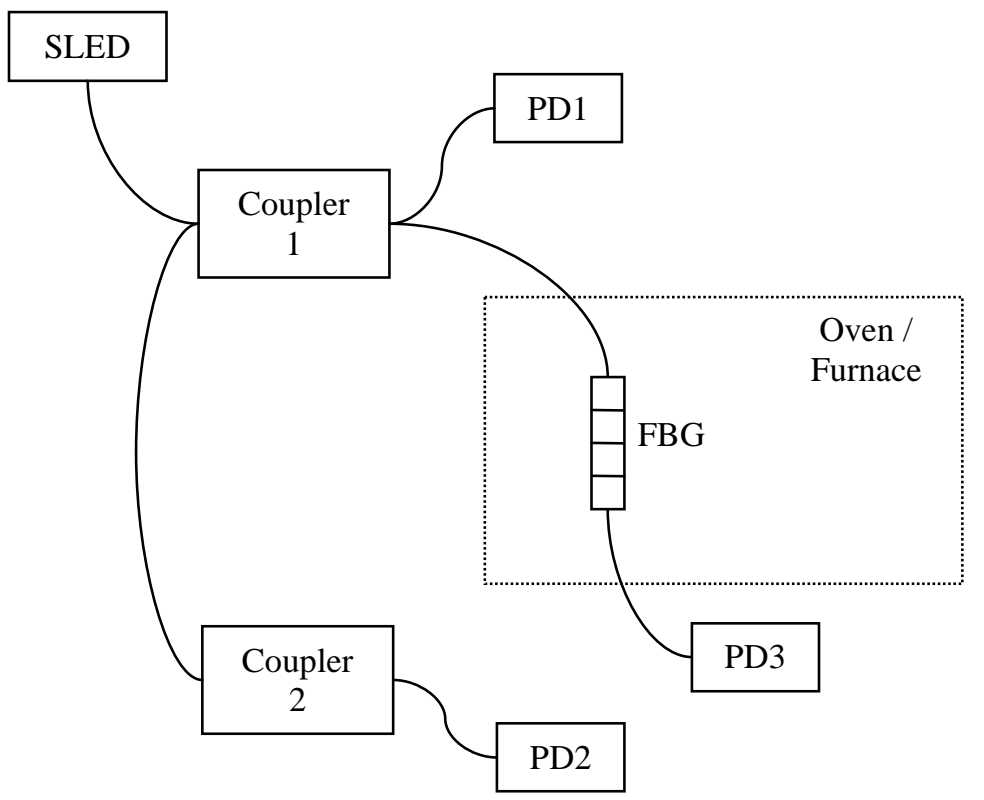

Figure 9.-FBG schematic with compensation for FBG reflected signal power variations. 
Public reporting burden for this collection of information is estimated to average 1 hour per response, including the time for reviewing instructions, searching existing data sources, gathering and maintaining the data needed, and completing and reviewing the collection of information. Send comments regarding this burden estimate or any other aspect of this collection of information, including suggestions for reducing this burden, to Washington Headquarters Services, Directorate for Information Operations and Reports, 1215 Jefferson Davis Highway, Suite 1204, Arlington, VA 22202-4302, and to the Office of Management and Budget, Paperwork Reduction Project (0704-0188), Washington, DC 20503.

\begin{tabular}{|l|l|l|}
\hline 1. AGENCY USE ONLY (Leave blank) & $\begin{array}{c}\text { 2. REPORT DATE } \\
\text { January } 2004\end{array}$ & $\begin{array}{r}\text { 3. REPORT TYPE AND DATES COVERED } \\
\text { Technical Memorandum }\end{array}$ \\
\hline
\end{tabular}

\section{TITLE AND SUBTITLE}

\section{FUNDING NUMBERS}

Performance Evaluation of Fiber Bragg Gratings at Elevated Temperatures

6. AUTHOR(S)

Jeffrey Juergens, Grigory Adamovsky, and Bertram Floyd

\section{PERFORMING ORGANIZATION NAME(S) AND ADDRESS(ES)}

National Aeronautics and Space Administration

John H. Glenn Research Center at Lewis Field

Cleveland, Ohio 44135-3191

9. SPONSORING/MONITORING AGENCY NAME(S) AND ADDRESS(ES)

National Aeronautics and Space Administration

Washington, DC 20546-0001
WBS-22-708-87-08

8. PERFORMING ORGANIZATION REPORT NUMBER

E-14303

\section{SUPPLEMENTARY NOTES}

Prepared for the Photonics East Symposium sponsored by the International Society of Optical Engineering, Providence, Rhode Island, October 27-30, 2003. Jeffrey Juergens and Grigory Adamovsky, NASA Glenn Research Center; and Bertram Floyd, Akima Corporation, Fairview Park, Ohio 44126. Responsible person, Grigory Adamovsky, organization code 5520, 216-433-3736.

Unclassified - Unlimited

Subject Categories: 06, 19, 35, and 74

Distribution: Nonstandard

Available electronically at http://gltrs.grc.nasa.gov

This publication is available from the NASA Center for AeroSpace Information, 301-621-0390.

\section{ABSTRACT (Maximum 200 words)}

The development of integrated fiber optic sensors for smart propulsion systems demands that the sensors be able to perform in extreme environments. In order to use fiber optic sensors effectively in an extreme environment one must have a thorough understanding of the sensor's limits and how it responds under various environmental conditions. The sensor evaluation currently involves examining the performance of fiber Bragg gratings at elevated temperatures. Fiber Bragg gratings (FBG) are periodic variations of the refractive index of an optical fiber. These periodic variations allow the FBG to act as an embedded optical filter passing the majority of light propagating through a fiber while reflecting back a narrow band of the incident light. The peak reflected wavelength of the FBG is known as the Bragg wavelength. Since the period and width of the refractive index variation in the fiber determines the wavelengths that are transmitted and reflected by the grating, any force acting on the fiber that alters the physical structure of the grating will change what wavelengths are transmitted and what wavelengths are reflected by the grating. Both thermal and mechanical forces acting on the grating will alter its physical characteristics allowing the FBG sensor to detect both temperature variations and physical stresses, strain, placed upon it. This ability to sense multiple physical forces makes the FBG a versatile sensor. This paper reports on test results of the performance of FBGs at elevated temperatures. The gratings looked at thus far have been either embedded in polymer matrix materials or freestanding with the primary focus of this paper being on the freestanding FBGs. Throughout the evaluation process, various parameters of the FBGs performance were monitored and recorded. These parameters include the peak Bragg wavelength, the power of the Bragg wavelength, and total power returned by the FBG. Several test samples were subjected to identical test conditions to allow for statistical analysis of the data. Test procedures, calibrations, and referencing techniques are presented in the paper along with directions for future research.

\section{SUBJECT TERMS}

15. NUMBER OF PAGES

Fiber optics; Fiber-optic instruments; Fiber Bragg grating; Annealing; Thermal cycle; Temperature sensors; Strain sensors

\begin{tabular}{|c|c|}
\hline $\begin{array}{c}\text { 17. SECURITY CLASSIFICATION } \\
\text { OF REPORT } \\
\text { Unclassified }\end{array}$ & $\begin{array}{c}\text { 18. SECURITY CLASSIFICATION } \\
\text { OF THIS PAGE } \\
\text { Unclassified }\end{array}$ \\
\hline
\end{tabular}

\section{SECURITY CLASSIFICATION OF ABSTRACT}

Unclassified
15

16. PRICE CODE
Standard Form 298 (Rev. 2-89)

\section{LIMITATION OF ABSTRACT}

Prescribed by ANSI Std. Z39-18 298-102 